\title{
LA SINGULARIDAD EN LA ANTROPOLOGÍA VALENTINIANA
}

\author{
Mariano Troiano \\ Facultad de Filosofía y Letras. UNCuyo. Argentina
}

Resumen: La soteriología gnóstica indica que aquellos que alimenten el elemento espiritual interiorizando el conocimiento serán salvados. Ello ha sido interpretado como una antropología estática que divide la humanidad en tres tipos de naturalezas fijas y a cada una corresponde un tipo preestablecido de salvación o condena. Confusión que proviene de diferentes concepciones sobre la singularidad del hombre. En el presente trabajo, buscaremos fundamentar dicha hipótesis comparando la postura del Ireneo de Lyon, a través de su obra Contra las Herejías, con aquella de los textos gnósticos: Evangelio de la Verdad (NH I, 3), el Tratado de la Resurrección (NH I, 4) y el Apócrifo de Santiago (NH I, 2).

Palabras clave: Ireneo de Lyon - Valentinismo - Antropología - Naturaleza Salvación

\section{THE UNIQUENESS IN THE VALENTINIAN ANTHROPOLOGY}

\begin{abstract}
Gnostic soteriology indicates that those who nourish the spiritual element by internalizing knowledge will be saved. This has been interpreted as a static anthropology that divides humanity into three types of fixed natures and each corresponds to a pre-established type of salvation or condemnation. Confusion that comes from different conceptions about the uniqueness of man. In the present work, we will seek to base this hypothesis by comparing the position of Irenaeus of Lyons in Against Heresies with that of the Gnostic texts: Gospel of Truth (NH I, 3), the Treatise on the Resurrection (NH) I, 4) and the Apocryphon of James (NH I, 2).
\end{abstract}

Keywords: Irenaeus - Valentinianism - Anthropology - Nature - Salvation

Recibido: 8.07.18 - Aceptado: 15.01.19 


\section{Correspondencia: Mariano Trioano.}

Email: mariantro@hotmail.com

Doctor en la Facultad de Filosofía y Letras de la Universidad Nacional de Cuyo.

Dirección institución: Centro Universitario Parque General San Martín s/n

M5502JMA. Mendoza, Argentina

Dirección postal y teléfono: Paso de los Andes 262 dpto 3 (5500) Mendoza,

Argentina- 0054261 4200768- Movil: 005492613830873

ID ORCID: https://orcid.org/0000-0001-6697-181X

\section{Introducción ${ }^{1}$}

n un artículo publicado en la revista Teología y Vida, titulado
"De la substancia del diablo'. Orígenes y la dinámica del
sistema valentinano de las tres naturalezas" (Troiano, 2014) propuse confrontar la visión heresiológica del pensador alejandrino con fuentes gnósticas. Orígenes no solo explica que para los valentinanos los hombres se encuentran divididos en tres naturalezas (material, psíquica y espiritual), sino que afirma que dichos pensadores dan un destino final inmutable a cada uno de los grupos así conformados. Estudiosos de la talla de Enrico Norelli han abordado el tema (Norelli, 1992), sin, por lo tanto, profundizar sus argumentos a través del análisis de las fuentes aportadas por la Colección de Nag Hammadi; análisis que sí ha sido realizado por especialistas del gnosticismo, tales como Jean Daniel Dubois (Dubois, 2011, 59-78) y Michel Williams (Williams, 1996, 96-138).

En el mencionado trabajo, afirmé que Orígenes basa dicha crítica antropológica en una lectura particular del maestro valentiniano Heracleón, con un claro intento de contraponerla a la propia, que considera la diferencia entre los seres como dependiente de la fidelidad de sus movimientos en relación con su origen divino (Peri Archôn I, 8, 2. Crouzel - Simonetti (eds.), 1978, 225). Dicha postura, es coherente con su argumentación en favor de la libertad del hombre, responsable ante Dios de sus actos (Peri

1 Este trabajo incorpora resultados presentados en el workshop internacional "Irreductibilidad y Persona" realizado en Santiago de Chile (2016) en el marco del proyecto de investigación interdisciplinar "Singularidad. Convergencia de filosofía, teología y ciencia" de la Universidad Católica del Maule, financiado por Templeton Foundation y adjudicado por el Proyecto "Science, Philosophy and Theology: Capability Building in Latin America" de la Universidad de Oxford. 
Archôn I, 6, 2. Crouzel - Simonetti (eds.), 1978, 199; Blanc, 1996, 26). En efecto, el concepto de libre albedrio ( $\tau$ ò $\alpha$ $\tau \varepsilon \xi o v ́ \sigma ı v$ ) es clave en el sistema salvífico del alejandrino. Los diferentes grados de naturalezas provienen

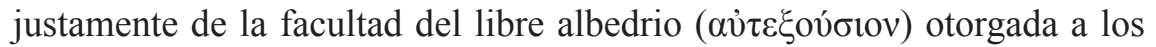
seres racionales y su voluntad de progresar hacia la imitación divina o de caer como consecuencia de su abandono (Peri Archôn II, 9, 6. Crouzel Simonetti (eds.), 1978, 364-365). De esta libertad de los seres racionales, afirma Orígenes, se deriva la diversidad del universo (Peri Archôn II, 9, 6. Crouzel - Simonetti (eds.), 1978, 366-367)2.

Dada la importancia otorgada a la libertad por Orígenes, entendemos porque este condena de manera tan enérgica la postura aparentemente determinista de Heracleón. Desgraciadamente no poseemos otra fuente del pensamiento del maestro valentiniano que los textos transmitidos por Orígenes y es por ello que en el mencionado trabajo propuse confrontar la interpretación patrística con un famoso texto valentiniano, el Tratado Tripartito (NH I, 5). Dicha comparación me permitió afirmar en la conclusión, que es el hombre en tanto que individuo, y no la humanidad en su conjunto, quien está constituido por tres naturalezas en constante tensión y que para entender el sistema dinámico valentiniano, es indispensable tener en cuenta, "que la tensión que esta triple relación conlleva es necesaria a la economía salvífica establecida por el Padre" (Troiano, 2014, 626). En efecto, estando el hombre compuesto por los tres elementos, es la gnosis revelada por el salvador y su interiorización aceptada o rechazada por los individuos, lo que manifiesta la preponderancia de un elemento sobre los otros dos. Es decir, se trata de una unidad antropológica y de una jerarquización soteriológica, dónde la dinámica del sistema se ve claramente reflejada en la actitud del elemento psíquico que, ante la revelación, puede inclinarse tanto al bien como al mal (TraTrip 119, 22-23. García Bazán (trad.), 2000, 202).

Propongo entonces, continuar dicho análisis ya que considero que Orígenes, al igual que su predecesor, Ireneo de Lyon, traslada una concepción valentiniana sobre la soteriología (solo aquellos que hayan alimentado el elemento espiritual interiorizando la gnosis serán salvados) $)^{3}$ y la impone

2 Cf. Con la degradación de la inteligencia del alma en Peri Archôn II, 8, 3-4 y $9,2$.

3 “[...] es por el fruto (nескарпос) que se reconoce la esencia de cada una de las tres razas (пı)OMNT̄Nrenoc)". TraTrip 118, 21-23. García Bazán (trad.), 2002, 
sobre una concepción antropológica (la humanidad se divide en tres tipos de naturalezas fijas y a cada una corresponde un tipo de salvación) (Peri Archôn I, 8, 2. Crouzel -Simonetti (eds.), 1978, 223 e In Jo., XIX, XIV, 90, Blanc, 1982, 102-103). Esta confusión, aparentemente intencional, del pensamiento valentiniano proviene de diferentes concepciones sobre la singularidad del hombre y acentos disímiles sobre el elemento constitutivo que lo define como distinto a los otros seres de la creación.

Nos guía en nuestro objetivo el intento de reformular algunos de los preceptos considerados como fundamentales y definitorios del pensamiento gnóstico. Conceptos que durante décadas han guiado a los estudiosos ${ }^{4}$ y que aún hoy es necesario dilucidar, pues se fundamentan ya sea en una visión parcial de las fuentes (centrándose principalmente en textos patrísticos) o en un desconocimiento de la variedad intrínseca a las diversas corrientes gnósticas. En efecto, el análisis de la historia de la investigación, llevado adelante por Karen King, nos permite entender este proceso de cambio al mismo tiempo que puntualiza la necesidad de continuar difundiendo este tipo de trabajos para explicar dichos conceptos y evitar los vicios que todavía persisten en los medios académicos (King, 2003, 55-215 y Williams, 1996, 96, 115).

Explicitada nuestra meta, en el presente trabajo, buscaremos fundamentar dicha hipótesis sobre la singularidad del hombre, comparando la postura del Ireneo de Lyón a través de su obra, Contra las Herejías, primer gran tratado heresiológico que nos ha llegado hasta la actualidad, con aquella expuesta por los textos gnósticos que les son contemporáneos tales como el Evangelio de la Verdad (NH I, 3) Tratado de la Resurrección (NH I, 4) y el Apócrifa de Santiago (NH I, 2).

\section{Ireneo de Lyon}

202; Painchaud-Thomassen (trad.), 1989, 212-213 y Painchaud-Thomassen (trad.), 2007, 188.

4 Es el caso del sostenido "anticosmismo radical" de los textos gnóstico, incluido por Ugo Bianchi en su definición del fenómeno, basándose para ello fundamentalmente en textos pertenecientes al llamado gnosticismo "setiano" cuya reconstitución por parte de los investigadores actuales es puesta en duda (Dubois, 2011, 157-165). A modo de ejemplo: "Selon notre opinión, le gnosticisme, pour ce qui est de son anticosmisme et de sa doctrine dualiste de l'homme ( $\sigma \tilde{\omega} \mu \alpha \sigma \tilde{\eta} \mu \alpha$, corps=tombeau) que le définit pour une bonne partie [...]", (cursivas del autor), (Bianchi, 1970, 116-138). 
En su obra "Contra las Herejías" escrita hacia el tercer cuarto del siglo II, Ireneo, obispo de Lyon, describe en el libro I, el pensamiento de numerosas corrientes gnósticas. Sin embargo, su fuente principal y el centro de su ataque, es la doctrina del valentiniano Tolomeo (Adv Haer. I, 1, 1) a la cual el heresiólogo intercala variantes más o menos radicales provenientes de otras escuelas (I, 2,3 y más claro en I, 11, 1-5). En los restantes cuatro volúmenes de su obra, el lionés refutará dichas concepciones.

Es así como, criticando los argumentos gnósticos que, según Ireneo, establecen la existencia de entidades separadas llamadas Cristo y Jesús (III, 16,1), el Padre de la Iglesia expone:

"Así pues, como hemos demostrado, hay un solo Dios Padre, y un solo Cristo Jesús nuestro Señor, el cual vino para la salvación universal recapitulando ( $\alpha v \alpha \kappa \varepsilon \varphi \alpha \lambda \alpha 1 \omega \sigma \alpha ́ \mu \varepsilon v o \varsigma)$ todo en sí $($ Ef 1,10). En este "todo" está comprendido también el hombre, esa obra modelada

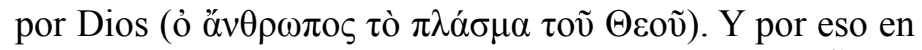

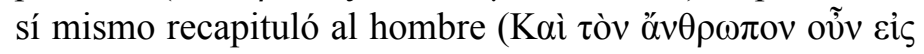

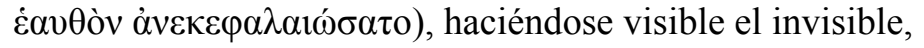
comprensible el incomprensible, pasible el impasible, y

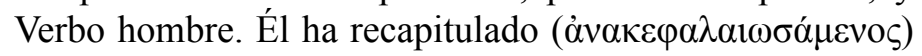
todas las cosas en sí mismo; para que, como el Verbo de Dios tiene el primado sobre las cosas supracelestes, espirituales e invisibles, así pueda tener el primado también sobre las cosas visibles y corporales (Col 1,18); para, asumir en sí el primado, darse a sí mismo a la Iglesia como Cabeza (Ef $1,22)$; para atraer a sí todas las cosas en el tiempo oportuno (Jn 12,32)" (Adv. Haer. III, 16, 6. Rousseau-Doutreleau (eds.), 2002², 312-315) ${ }^{5}$.

No tenemos aquí la posibilidad de ahondar en la cristología establecida por Ireneo en contraposición con la valentiniana tal cual es descripta por él y tal cual aparece en las fuentes. Sin embargo, destacaremos algunos puntos de dicha cristología que tienen relación directa con el tema de la antropología valentiniana que ocupa este estudio. Es evidente que para el obispo lionés la cristología tiene una vinculación directa con la

5 Sobre la "recapitulación” ver Bobichon (ed.), 2003, 830, nota 20. 
antropología y la soteriología. Jesús como Hijo de Dios, ha resumido en su persona la materialidad humana y la esencia divina. Esta doctrina es, según Ireneo, esencial para los fines salvíficos. De acuerdo con el lionés, los gnósticos eliminan las posibilidades soteriológicas que dicha identificación ofrece a los hombres al dividir la unidad de Cristo en diferentes entidades (por un lado Jesús, por otro Cristo o incluso el Unigénito, el Verbo o el Salvador). Se trata de una doctrina destructiva que desvía a la humanidad de la concepción soteriológica del Hijo de Dios: "[...] cuya doctrina (i.

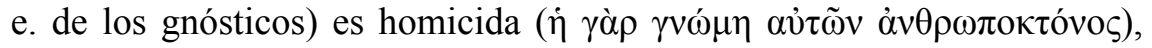
pues imaginan muchos Dioses y fingen muchos Padres, y según muchos aspectos reducen y dividen al Hijo de Dios" ( $A d v$. Haer. III, 16, 8. RousseauDoutreleau (eds.), 2002², 318-319) .

La relación intrínseca entre antropología y soteriología se fundamenta a través de una visión particular del origen del hombre. Así, el nacimiento virginal de Jesús, es para el obispo de Lyon, la recapitulación

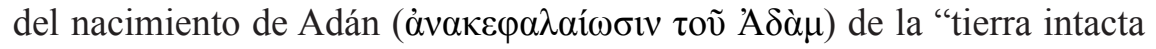

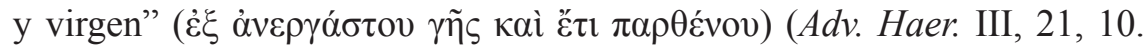
Rousseau-Doutreleau (eds.), 2002², 428-429). De esta manera, tal como el primer hombre tomo su materialidad de la tierra, así lo hizo Cristo de su madre:

"Lo mismo es afirmar que apareció (i.e. Jesús) como un hombre sin ser hombre, y decir que se hizo hombre sin tomar nada del hombre. Porque si no tomó del hombre la substancia de la carne, tampoco se hizo hombre ni Hijo del Hombre. Y si no se hizo aquello mismo que nosotros somos, no hizo gran cosa el sufrimiento de su pasión. Pero somos un cuerpo tomado de la tierra y un alma que recibe de Dios el espíritu: todo hombre, el que sea lo convendrá. Así pues, es eso mismo en lo que ha devenido el Verbo de

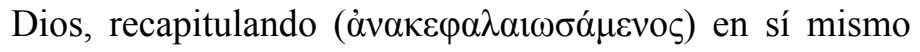
la propia obra por él modelada" (Adv. Haer. III, 22, 1. Rousseau-Doutreleau (eds.), 2002², 430-433).

Asumir la materialidad del hombre iniciada con Adán deviene un

6 Sobre la metodología utilizada por Ireneo, ver Alain Le Boulluec: Le Boulluec, 1985, 235. 
elemento capital para los fines salvíficos de la Pasión. Sin la humanidad asumida en la encarnación, el sufrimiento en la Cruz carece de sentido. Ahora bien, en el sistema ireneano la recapitulación establecida por Cristo implica tanto las naturalezas humanas como la Historia misma.

"De ahí que Pablo llame a Adán "tipo del que ha de venir" (Rom 5,14), porque el Verbo, Artesano del Universo, había prefigurado en Adán la futura economía de la humanidad de la cual se revestiría el Hijo de Dios, Dios habiendo planeado en primer lugar al hombre psíquico ( $\tau$ òv $\psi v \chi$ ¡ kòv àv $\theta \rho \omega \pi \mathrm{ov})$, con el fin evidente que sea salvado por el

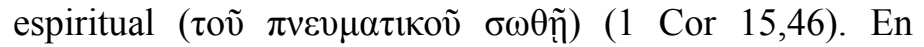
efecto, porque existía ya aquel que salvaría, era necesario que aquel que sería salvado existiera también, para que el Salvador no fuese estéril" (Adv. Haer. III, 22, 3. RousseauDoutreleau (eds.), 2002², 438-439).

No se trata solamente de establecer la necesidad de la encarnación, sino la unidad del ser humano. Dicha unidad se manifiesta en III, 17, 1, donde Ireneo explica el relato evangélico del descenso del Espíritu en forma de paloma (Mat. 3,16, Mc 1, 10 Lc 3,22 y Jn 1.32), indicando que el espíritu desciende para habitar en el hombre, criatura de Dios: "[...] renovándolo de hombre viejo a nuevo en Cristo" (Rousseau-Doutreleau (eds.), 2002², 330-331).

La encarnación es, entonces, esencial para poder realizar la misión soteriológica. Cristo debe asumir todos los elementos de la humanidad y muestra en su recapitulación el camino a seguir: "Pues nuestros cuerpos recibieron la unidad por medio de la purificación (bautismal) para la incorrupción ( $\alpha \varphi \theta \alpha \rho \sigma i ́ \alpha)$; y las almas la recibieron por el Espíritu. Por eso una y otro fueron necesarios, pues ambos contribuyen a dar la vida de Dios ( (eds.), 2002², 332-333). Esta concepción se opone a la que Ireneo descubre en la doctrina valentiniana, que afirma que el Verbo solo se manifestó en apariencia, "[...] no naciendo en la carne ni haciéndose verdaderamente hombre" (Adv. Haer. III, 18, 7, Rousseau-Doutreleau (eds.), 2002², 366367) y luego en el mismo párrafo: "Pero si no se hizo carne sino apariencia de carne, entonces no era verdadera su obra. ¡No! Lo que parecía, eso era: el Dios del hombre recapitulaba en sí su antigua creación, para matar por 
cierto el pecado, dejar vacía la muerte $(2$ Tim 1,10$)$ y dar vida al hombre. Por eso « sus obras son verdaderas » (Dt 32,4)" (Adv. Haer. III, 18, 7. Rousseau-Doutreleau (eds.), 2002², 370-371) ${ }^{7}$.

Así, para el lionés, Cristo resume al hombre, su pecado y la totalidad de su naturaleza triple (espíritu, alma y cuerpo). En Ireneo, la soteriología implica la antropología:

"En cuanto hombre, lo era para ser tentado; en cuanto Verbo, para ser glorificado; el Verbo se reposó para que pudiera ser tentado, deshonrado, crucificado y muerto, (1 Cor 15,5354; 2 Cor 5,4), habitando en aquel hombre que vence y soporta (el sufrimiento) y se comporta como hombre de bien y resucita y es subido al cielo. Este es el Hijo de Dios, Señor nuestro, Verbo existente del Padre e Hijo del Hombre porque nació de la Virgen María; que tuvo su origen de los hombres pues ella misma era un ser humano (äv $\theta \rho \omega \pi \circ \varsigma)$ tuvo la generación en cuanto hombre, y así llegó a ser Hijo del Hombre" (Adv. Haer. III, 19, 3, Rousseau-Doutreleau (eds.), 2002², 378-381).

Esta Cristología / Antropología unitaria del obispo es confrontada directamente con la interpretación que éste transmite sobre la triple división estática valentiniana de las naturalezas humanas, descripta en el libro I cuándo trata la creación gnóstica del hombre:

"Una vez fabricado el mundo, también hizo al ser humano, "sacado de la tierra" (Gén 2,7). No lo hizo de tierra seca, sino tomando algo de la substancia invisible, de la materia difusa y fluida, en la cual sopló el elemento psíquico. Este es el hombre hecho "a imagen y semejanza" (Gén 1,26). Ante todo según la imagen es el hombre hílico: cercano, pero no consubstancial a Dios. Según la semejanza es el hombre psíquico, a cuya substancia se le llama "espíritu de vida" (Gén 2,7), porque surge de un fluido espiritual. Y, dicen ellos, en tercer lugar la «túnica de piel» (Gén 3,21):

7 Ver en este sentido el apartado "L'hérésie comme négation de la foi", (Le Boulluec, 1985,184-185) 
ésta sería la carne sensible" ( $A d v$. Haer. I, 5, 5. RousseauDoutreleau (eds.), 1979, 86-89) ${ }^{8}$.

La exégesis gnóstica del Génesis transmitida por Ireneo, da origen a una antropología particular que atribuye a cada naturaleza un origen diferente:

De esta manera pretenden ellos que se haya originado el hombre que en ellos existe: recibió la psique del Demiurgo, el cuerpo del lodo y la carne de la materia; pero el hombre pneumático surgió de su Madre Achamot. 6. 1 Existen,

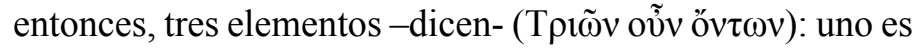

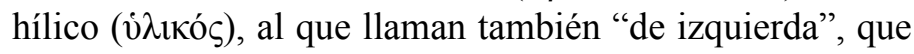
por necesidad perece, incapaz, como es, de recibir ningún

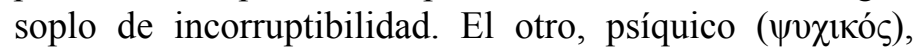
también llamado "de derecha", situado en medio, entre el hílico y el espiritual, que se inclinará hacia el lado que lo arrastre su propensión. En cuanto al elemento espiritual ( $\pi v \varepsilon v \mu \alpha \tau \iota \kappa o \varsigma)$, enviado para que, en conjunto con el psíquico, reciba aquí abajo su formación ( $\mu о \rho \varphi \eta ́)$, siendo instruido con este psíquico durante su estadía en él. ${ }^{9}$ Este elemento espiritual, dicen ellos, es "la sal" y "la luz del mundo" (Mt 5,1314) (Adv. Haer. I, 5, 6-6, 1. RousseauDoutreleau (eds.), 1979, 88-91).

Sin embargo, otra interpretación posible del fragmento del propio Ireneo, parece indicar por un lado que son tres los elementos que componen al ser humano y no tres tipos de hombres distintos. Pero, más importante aún, el lionés menciona que los autores gnósticos consideran necesario un proceso formativo tanto del elemento psíquico como del espiritual o pneumático. Este punto es esencial pues veremos su paralelo explícitamente

8 Sobre los argumentos de Ireneo y de los valentinianos sobre la emisión y la semejanza de naturalezas entre emitido y emitente ver Orbe, 1958, 635-654.

9 Los tres elementos repiten a su vez los tres momentos de la cosmogonía valentiniana ver Adv. Haer. I, 5, 1 (Rousseau-Doutreleau (eds.), 1979, 76-79). 
expuesto en los textos valentinianos contemporáneos. ${ }^{10}$

En el pasaje siguiente, el Padre de la Iglesia acentúa y detalla el aspecto dinámico del sistema valentiniano en relación directa con la misión soteriológica del Salvador, indicando además que se trata de tres sustancias que componen un mismo ser:

"Es necesario también, en efecto, para el elemento psíquico, una educación por los sentidos. ${ }^{11}$ Con este objeto el mundo habría sido fabricado y el Salvador habría venido en ayuda de este hombre psíquico, pues este está dotado de libre arbitrio ( $\alpha$ $\tau \varepsilon \xi o v ́ \sigma ı v)$, para salvarlo. Porque, dicen ellos, él ha tomado las premisas de lo que debía salvar: de Achamot el elemento espiritual, del Demiurgo el vestido psíquico que es Cristo y en fin, por motivo de la Economía se le preparó un cuerpo formado con substancia psíquica ( $\psi v \chi$ que pudiera ser visto, palpado y sufrir $(\pi \alpha \theta o \varsigma)$. En cuanto a la substancia hílica, él no ha tomado nada, dicen ellos, ya que la materia $(\tilde{v} \lambda \eta)$ nada tiene que pueda salvarse. La consumación vendrá cuando todo lo espiritual esté perfectamente formado mediante la gnosis. Estos son los hombres espirituales, que han adquirido el perfecto conocimiento de Dios y a quienes Achamot ha iniciado en los misterios. Ellos pretenden ser estos hombres" ( $A d v$. Haer. I, 6, 1. Rousseau-Doutreleau (eds.), 1979, 90-93).

Como ya establecimos no discutiremos aquí la interpretación ireneana de la particular cristología gnóstica, del componente psíquico que representa Cristo y de la aparente negación terminante de su corporalidad. Sin embargo, es evidente que también existe entre los valentinianos descriptos por Ireneo (y subrayo el "descriptos por”), no sólo un sistema dinámico, sino también una correspondencia particular

10 Si bien Enrico Norelli destaca también este punto, detiene aquí su análisis, mientras que nosotros proponemos continuarlo para intentar avanzar respuestas a las preguntas planteadas por el autor italiano. (Norelli, 1992, 19 y 29).

11 Sobre las diferentes traducciones de $\tau \tilde{\varphi} ~ \psi v \chi \imath \kappa \tilde{\varphi}$ y la elección de los editores ver Rousseau-Doutreleau (eds.), 1979, 201-204. 
entre antropología, soteriología y escatología ${ }^{12}$.

Sin embargo, Ireneo no parece percibir la interrelación dinámica del sistema y considera que la relación directa entre antropología y soteriología conlleva a una salvación predeterminada según sus naturalezas.

"Por otra parte, hay enseñanzas psíquicas, que son las que han recibido los hombres psíquicos, es decir aquellos que, mediante la fe sencilla y las obras han sido confirmados, pero no tienen la gnosis perfecta: éstos somos los hombres que, según ellos, formamos la Iglesia. Por eso nos hace falta una buena conducta, pues de otra manera no podremos salvarnos. En cuanto a ellos, no se salvan por las obras, sino que, por el hecho de ser de naturaleza espiritual, se salvan por principio ( $\left.\pi \alpha \dot{v} \tau \omega \varsigma \sigma \omega \theta \eta ́ \sigma \varepsilon \sigma \theta \alpha \_\delta o \gamma \mu \alpha \tau i \zeta \zeta o v \sigma \imath v\right)$. Porque,

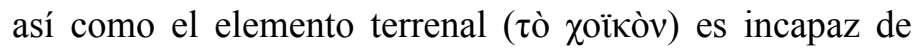
acoger la salvación -por no tener en sí -dicen- la capacidad de recibirla-; de igual manera, el elemento espiritual -y de esta clase pretenden ser ellos- es incapaz de corromperse, sean cuales fueren sus actos". (Adv. Haer. I, 6, 2. RousseauDoutreleau (eds.), 1979, 92-95) $)^{13}$.

La salvación "automática" de la naturaleza espiritual parece desdecir lo afirmado anteriormente por el propio lionés sobre la necesidad

12 Esta relación está claramente expresada en el párrafo siguiente: "Entonces los

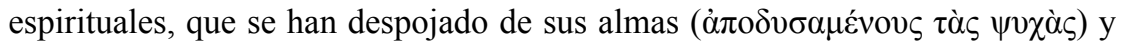

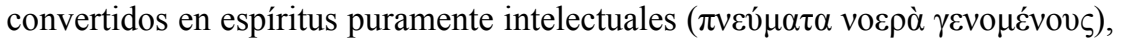
entrarán en el Pléroma para convertirse en esposas de los Ángeles que forman el entorno del Salvador. A su vez el Demiurgo pasará al lugar de su Madre la Sabiduría, que es el Intermedio. También las almas de los justos descansarán en el Lugar Intermedio; pues nada psíquico puede ingresar dentro del Pléroma. Una vez que todo esto se haya realizado, el fuego escondido en la tierra se encenderá y apoderándose de toda la materia la consumirá, y él mismo, consumiéndose con ella, irá a la nada". Adv. Haer. I, 7, 1 (Rousseau-Doutreleau (eds.), 1979, 100-103). Sobre la primacía de la soteriología sobre la teología y la cosmología gnósticas ver Le Boulluec, 1985, 240.

13 Incluso en I 6. 3 y 4 Ireneo acusa que, dada esta concepción determinista, los pneumáticos se sienten libres de realizar en vida todo tipo de pecados. (Rousseau-Doutreleau (eds.), 1979, 94-101). 
de formación de dicho elemento. Incluso, este determinismo soteriológico parece matizar lo expuesto anteriormente sobre los elementos constitutivos del ser humano (I, 5, 6- 6, 1). En efecto, en este párrafo Ireneo afirma una división gnóstica de la raza humana por categorías esenciales:

"Enseñan, pues, que son tres los tipos de seres humanos: los pneumáticos, los psíquicos y los terrenales, como fueron Caín, Abel y Set, de modo que éstos representan las tres naturalezas, no de un solo individuo, sino de toda

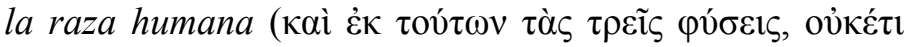

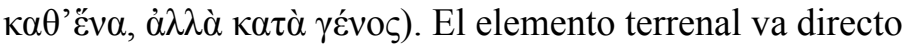
a la corrupción. El psíquico, si elige las cosas mejores, descansará en el Lugar Intermedio; pero si elige las más bajas, también acabará como aquellas cosas de las que se ha hecho semejante. En cuanto a los elementos pneumáticos que Achamot, siembra desde el principio hasta hoy, en las almas justas, luego que han sido educados y desarrollados aquí abajo, ya que son envidados muy pequeños, y después que han sido juzgados dignos de la perfección, ellos serán dados como esposas a los Ángeles" (Adv. Haer. I, 7, 5. Rousseau-Doutreleau (eds.), 1979, 110-111) ${ }^{14}$.

Es decir, ya no se trataría de una constitución tripartita de elementos, sino de un único elemento que define a cada individuo. Ahora bien, dicha concepción se acentúa en las líneas que siguen al párrafo anterior en las cuales Ireneo afirma la inflexibilidad del sistema valentiniano en lo referente a la categoría o elemento psíquico: “[...] Finalmente distinguen las almas en dos categorías: las que son buenas

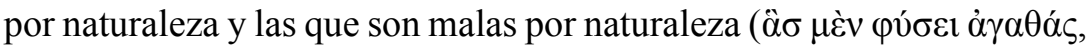

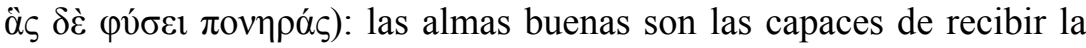
semilla; en cambio las de naturaleza mala nunca podrán ser capaces de acogerla" (Adv. Haer. I, 7, 5. Rousseau-Doutreleau (eds.), 1979, 112113).

Así, la tendencia del individuo en el cual predomina el elemento psíquico está predeterminada "por naturaleza". Sin embargo, el lionés

14 Sobre los fundamentos técnicos de la heresiología llevada adelante por Ireneo ver Le Boulluec, 1985, 234. 
afirmaba más arriba (I, 5, 6) que este puede ser capaz de recibir la semillaespíritu y "formarse" por la gnosis e inclinarse según su propensión y por lo tanto recibir la salvación. Lo cual explicita en I, 6, 1 citado más arriba: "el Salvador habría venido en ayuda de este hombre psíquico, pues este está dotado de libre arbitrio, para salvarlo." Entonces, ¿para qué sirve la instrucción y formación del hombre psíquico? ¿Para qué se le otorga el libre arbitrio si está condenado de antemano?, y en este mismo sentido ¿Por qué es necesaria la formación del hombre espiritual si es salvado por naturaleza? (I, 5, 6-6, 1)

Veremos a continuación como los textos gnósticos polemizan con las interpretaciones transmitidas por Ireneo y plantean un sistema coherente y complejo, diferente al descripto por el lionés.

\section{Textos Gnósticos}

\section{Fragmentos del pensamiento de Valentín}

El artículo de Enrico Norelli citado anteriormente, "Marcione e gli gnostici sul libero arbitrio, e la polemica di Origene" concluye en "la simplificación al exceso de la complejidad de la posición gnóstica (i.e. valentiniana) sobre el libre arbitrio" ${ }^{15}$. Esta postura, coincidente con nuestra conclusión en el artículo mencionado al inicio de nuestra exposición; sin embargo, carece en su argumentación de dos elementos esenciales. Por una parte, lo que intentamos establecer en el presente trabajo, que se trata una postura persistente en la heresiología con respecto al sistema valentiniano, tal cual veremos en el caso de Ireneo. Por otra parte, el autor italiano utiliza principalmente fuentes patrísticas para la reconstrucción de sistemas gnósticos y secundariamente hace mención a fuentes gnósticas. Considero, que un análisis detallado de dichas fuentes puede explicar mejor la mencionada simplificación, al mismo tiempo que mostrar la coherencia del cristianismo valentiniano.

Por otra parte, si bien Norelli afirma brevemente que el libre arbitrio está presente tanto en el elemento psíquico como en el elemento

15 Norelli, 1992, 29. Por otra parte, si bien, Norelli retoma posturas académicas que cuestionan la afirmación de la "salvación por naturaleza", ellas consideran que el elemento pneumático, es otorgado por gracia divina y no es constituyente del hombre desde sus orígenes. Postura que el autor parece compartir (Norelli, 1992, 7-12), pero que también puede ser desmentida por el análisis de las fuentes gnósticas (Troiano, 2014, 617-623). 
espiritual, se limita solamente a plantear la pregunta sobre la posibilidad de caída de este último (Norelli, 1992, 13-14 y 18-19). ${ }^{16}$ Nosotros creemos poder contestar dicha pregunta tanto en el artículo mencionado como en el presente, considerando que la esencia, es decir la naturaleza entendida como condición predominante del hombre, se revela de acuerdo con la aceptación del mensaje gnóstico transmitido por el Salvador.

Entonces, es nuestra intención en este apartado matizar las interpretaciones de Ireneo de Lyon en lo referente a la categorización valentiniana de la raza humana y su sistema determinista de salvación. Sin embargo, antes de abordar las fuentes gnósticas es necesario indicar que sus concepciones no aparecen explicitadas en sus textos, sino que el investigador debe avanzar desentrañando un lenguaje filosófico, mitológico y religioso para poder encontrar pistas que poco a poco vayan tejiendo una imagen coherente, para lo cual es necesario contextualizar dichas menciones. ${ }^{17}$

En busca de la concepción valentiniana sobre la unidad antropológica abordaremos en primer lugar las pocas fuentes que han llegado hasta nosotros pertenecientes al fundador de la corriente. Valentín ejerce su actividad en Roma hacia 136-160 d.C. (Justino, Dial. 35, 6 e Ireneo, Adv. Haer. III 4, 3. Thomassen, 2006, 17-18). Los fragmentos que podemos analizar en la actualidad provienen de la obra Stromata de Clemente de Alejandría (hacia finales s. II y principios s. III) y de Philosophumena de Hipólito de Roma (principios del s. III). Sin embargo, Einar Thomassen considera que existen grandes posibilidades que el Evangelio de la Verdad (NH I, 3) y el Tratado sobre la Resurrección (NH I, 4) sean también obras de Valentín (Thomassen, 2006, 424).

Entre los fragmentos de autoría de Valentín, nos interesa principalmente, el número 8, un salmo conservado por Hipólito (Refutación de todas las herejías VI 37, 7) que dice: "Verano. Yo veo como todo depende del espíritu, Yo percibo como todo ha nacido por el espíritu

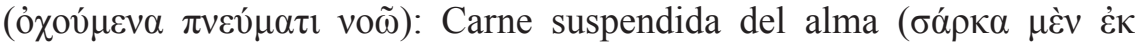

16 Incluso el autor plantea la pregunta sobre las posibilidades de un paralelismo entre Orígenes y sus adversarios gnósticos. Pregunta a la cual hemos respondido, bien que indirectamente, en nuestro artículo sobre el alejandrino (Troiano, 2014, 7 y $10-13)$.

17 Sobre la forma particular de exégesis gnóstica ver (Le Boulluec, 1985, 231 y Orbe, 1972, 3). 


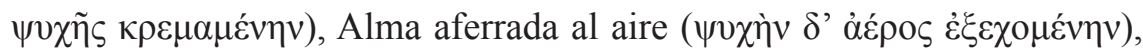

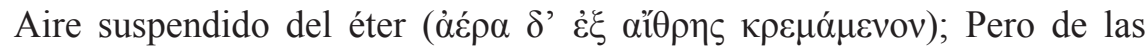

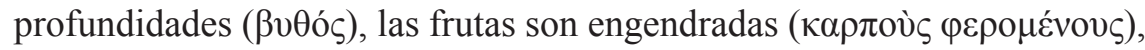

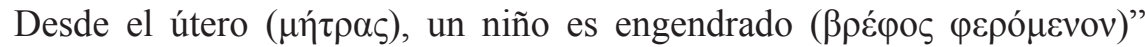
(Thomassen, 2006, 479).

Tal como lo expresa Thomassen la "cadena cósmica" reflejada por el salmo es una mezcla de términos antropológicos (carne y alma) con elementos físicos (aire y éter) que destaca el hecho que todo depende del espíritu (Thomassen, 2006, 481). Esta preeminencia, dice el autor, se acuerda con "la concepción valentiniana básica del cosmos como una estructura ordenada y jerarquizada establecida y mantenida por una fuerza espiritual" (Thomassen, 2006, 485). Dicha concepción nos permite inferir, de acuerdo con Thomassen que: "Valentín parece haber enseñado una doctrina inclusiva de la salvación: no hay distinción de niveles soteriológicos entre espirituales y psíquicos como habrá más tarde en el valentinismo occidental. Al contrario, todos los humanos están sujetos a la pasión y atormentados por demonios (fr. 2)" (Thomassen, 2006, 489).

Esta postura del fundador de la corriente, que contradice lo afirmado por Ireneo, puede ser corroborada en textos más extensos provenientes de la colección de Nag Hammadi.

\section{Evangelio de la Verdad (NH I, 3)}

El Evangelio de la Verdad es un texto perteneciente al Códice I de la Collección de Nag Hammadi y que podemos situar hacia el tercer cuarto del siglo II. Tal cual lo hemos indicado algunos estudiosos lo consideran un escrito de Valentín mismo (Thomassen, 2006, 424).

Einar Thomassen descubre en EvVer 18, 15, la clara importancia del Jesús histórico donde el texto habla de "el misterio oculto Jesús, el Cristo" (Pasquier- Thomassen (trad.), 2007, 57, nota 18, 5-11), mientras que en 20, 23-34 el evangelio afirma: "Por este motivo apareció Jesús, revistió aquel libro, fue clavado en un madero, y publicó el edicto del Padre sobre la cruz.

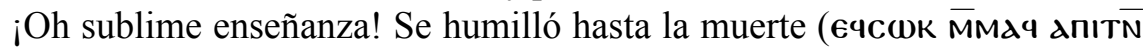

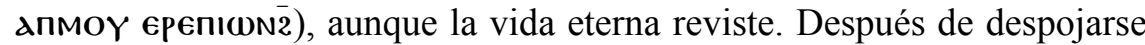
de estos harapos perecederos, se revistió de la incorruptibilidad que nadie puede sustraerle" (Attridge - MacRae (trad.), 1985, 86-89 y García Bazán (trad.), 1999, 149).

Es claro, tras la lectura del párrafo, que el texto no sólo indica el sufrimiento necesario del Hijo de Dios, un ser espiritual, sino que reivindica 
la importancia del Jesús histórico, tal cual se ha afirmado más arriba.

El estado fragmentario del texto dificulta su análisis. Sin embargo, en EvVer 31, 5-10 se indica: "Pues él (el Hijo) vino en una forma carnal (2їтоотC $\overline{\mathrm{N}}$ OYCגpz $\overline{\mathrm{N}} \mathrm{CM} \lambda \mathrm{T}$ ), sin encontrar ningún obstáculo a su desplazamiento puesto que la incorruptibilidad es irresistible" (Attridge - MacRae (trad.), 1985, 100-101 y García Bazán (trad.), 1999, 155). Y en el códice XII, el mismo párrafo se encuentra modificado: "Él estaba en lo carnal, presentando un aspecto extranjero [...] (NEq2 $\bar{N}$ пCMOT NCAPz

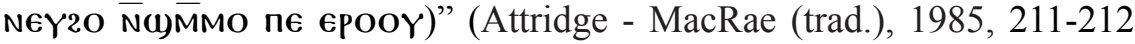
y Pasquier- Thomassen (trad.), 2007, 82). A propósito de este párrafo Thomassen explica que en "el EvVer, la encarnación del Salvador no es un simple engaño (como en ciertas fuentes gnósticas) sino que tiene una profunda soteriología" (Pasquier- Thomassen (trad.), 2007, 70 nota 30, 36$31,7)$.

Los valentinianos (o Valentín mismo), entonces, no niegan la encarnación de Cristo, sino que al contrario la revindican como un elemento soteriológico esencial, tal cual lo afirma el texto que sigue al Evangelio de la Verdad en el códice I, el Tratado de la Resurrección (NH I, 4).

\section{Tratado de la resurrección (NH I, 4)}

El Tratado de la Resurrección es un texto epistolar valentiniano que responde a un envío previo, al cual Jean Pierre Mahé, ubica entre 150 y 180 (Mahé (trad.), 2007, 94). ${ }^{18}$ El José Montserrat Torrents indica que el Tratado muestra una postura muy cercana a la expuesta por la ortodoxia antes de la denuncia de Ireneo (Montserrat Torrents - Quevedo (trad.), 2000, 95).

En él leemos en 44, 18-25: “¿De qué manera se condujo el Señor mientras existía en la carne $(\overline{2 N} \operatorname{cop} z)$ y cuando se manifestó como Hijo de Dios?. Él vivió en ese lugar en el que tu habitas, hablando de la ley de la naturaleza (sin embargo, yo la llamo "muerte"). Y el Hijo de Dios

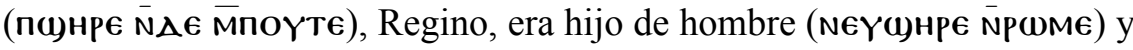

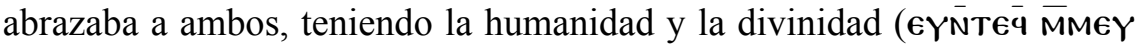

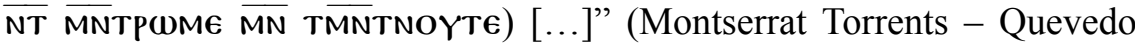
(trad.), 2000, 206 y Ménard, 1983, 44-45).

18 Cf. Lo expuesto por Montserrat Torrents y Quevedo, quienes lo atribuyen al "contexto del cristianismo helenizante del siglo III". (Montserrat Torrents Quevedo (trad.), 2000, 199). 
En nota a su traducción, José Montserrat Torrents destaca que en el texto aparece tanto "hijo de hombre" sin artículo como "el Hijo del Hombre" con artículo y agrega: "La primera expresión quiere indicar que Jesús era enteramente hombre y nacido como los demás hombres, mientras que la segunda expresión corresponde a uno de los títulos mesiánicos de Jesús en los Evangelio Sinópticos” (Montserrat Torrents - Quevedo (trad.), 2000, 206, nota 6 y Ménard, 1983, 62).

Unos párrafos más adelante, el Tratado de la Resurrección menciona: "Ésta es la resurrección espiritual (TdNACTdCıC N̄nENYMd) que absorbe a la psíquica del mismo modo que a la carnal (TIKH єCW $\overline{M N K}$

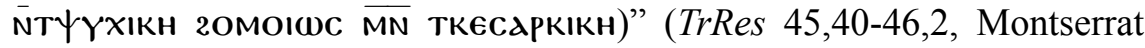
Torrents - Quevedo (trad.), 2000, 207). Jean-Pierre Mahé explica al respecto que "las resurrecciones carnales realizadas por Cristo son « una imagen de la resurrección espiritual » (Extr Teod. 7, 5). Ella no implica ni el cuerpo material, ni el alma psíquica, sino solamente la semilla espiritual" (Mahé, 2007, 101, nota 4539-46, 2). Mientras que Montserrat Torrents agrega que hay una carne que resucita, pero es una carne incorruptible, interior a la carne mundana y la esencia de esta carne es el pensamiento y el intelecto humanos y agrega:

"[...] "la carne incorruptible" - dice el autor- es vida, pensamiento e intelecto, es decir, es el alma. El maestro gnóstico, sin declararlo abiertamente, viene hacer coincidir en la resurrección la creencia en la inmortalidad del alma, en un intento de síntesis, de la concepción tradicional judaica y de la concepción helenística. Ahora bien, superior al alma es el espíritu, "el Todo que somos" (47,26-27), que es el que se salva. Pero el espíritu, en su salvación, arrastra "la carne", es decir, el alma. A diferencia de los valentinianos clásicos, el autor del tratado, del mismo modo que admite la realidad de la carne de Cristo, acepta la salvación pleromática del alma" (TrRes 46, 22-24. Montserrat Torrents - Quevedo (trad.), 2000, 203 y Ménard, 1983, 16-20 y 67).

Y más adelante afirma que para el autor del Tratado de la Resurrección "lo imperecedero en el hombre es su pensamiento y su intelecto. El autor traduce en términos filosóficos el significado de la resurrección pneumatiké. Expresada en estos términos, la doctrina de la 
resurrección no es muy distinta de la tesis platónica de la inmortalidad del alma racional" (Montserrat Torrents - Quevedo (trad.), 2000, 207, nota 17).

Observamos entonces, a través de la lectura conjunta y sucesiva del fragmento de Valentín y de los escritos que componen el códice I de la colección de Nag Hammadi (NH I, 3 y NH I, 4), no solo una coherencia en los temas tratados, sino un precisión paulatina en las concepciones antropológicas, cristológicas y soteriológicas expuestas por los mismos y coincidentes con nuestra descripción de un sistema de salvación dinámico, no por naturaleza sino de acuerdo a la interiorización de la gnosis.

\section{Apócrifo de Santiago (NH I, 1)}

Finalmente retrocederemos en el tiempo y en la estructura del Codice I abordando el texto del Apócrifo de Santiago (NH I, 2). Si bien el título no ha sido transmitido, las indicaciones del escrito establecen que se trata de una carta de contenido secreto (I, 9-10) (Rouleau (trad.), 2007, 13), en la cual Jesús responde a las cuestiones planteadas por sus discípulos. Donald Rouleau lo considera un texto gnóstico surgido en Alejandría entre mediados del siglo II y principios del III, pero no lo considera como propiamente valentiniano (Rouleau (trad.), 2007, 17-18). Sin embargo, el texto presenta elementos afines al valentinismo y así fue entendido por el compilador del Códice I, que lo ubica precediendo textos de esta corriente. Por otra parte, Francisco García Bazán, lo indica como "anterior a mediados del siglo II” (García Bazán (trad.), 1999, 294), lo cual si bien antecedería a Valentín mismo, nos transmite la antigüedad de la tradición interpretativa que éste revela en sus fragmentos (ApocSant 4,19-22. García Bazán (trad.), 1999, 294).

El texto indica claramente la composición tripartita del hombre: "Por lo tanto, sed llenos del Espíritu (nחNeץMd), pero faltos de la razón (плогос), porque la razón es el alma e igualmente psíquica (плогос $\overline{\mathrm{N}}$ г $\mathrm{P}$ пе тұүхн оүҰүхн)".(ApocSant 4,19-22. García Bazán (trad.), 1999, 299 y Rouleau (trad.), 2007, 29) ${ }^{19} \mathrm{Y}$ a continuación agrega:

19 Ver también Hechos 2.4 12-13 y lo expuesto por Rouleau y Roy (Rouleau-Roy (trad.), 1987, 44-45) 
"Porque conoce (el Padre) la voluntad de ellos (los hombres) y junto con ello, aquello que la carne (capz)

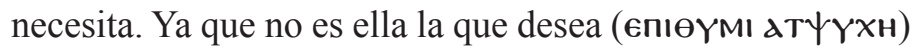
al alma? Efectivamente, sin el alma el cuerpo no peca (MApencWma $\bar{P}$ NABEI $\bar{N} \Theta 2 \epsilon$ ), igual que el alma no se salva

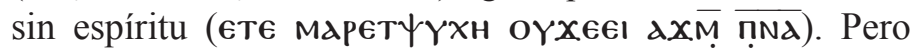
el alma se salva sin el mal y se salva también el espíritu ( $\overline{N 4 O Y} x \in \in I \bar{N} G 1 \Pi \pi \in \overline{\Pi N \alpha}$ ), el cuerpo se torna sin pecado

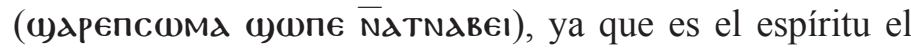
que vivifica al alma, el cuerpo, al contrario, es el que da muerte, o sea, que ella misma es la que se da muerte. En verdad os digo: no perdonará el pecado a ningún alma, ni ofensa a la carne, pues ninguno de los que hayan traído puesta (phorein) la carne se salvará." (ApocSant 11, 3512,5. García Bazán (trad.), 1999, 299; Rouleau (trad.), 2007, 37 y Rouleau-Roy (trad.), 1987, 72-75).

Nos dice Rouleau: "El cuerpo es un elemento moralmente u ontológicamente indeterminado ya que su pecado o su ausencia de pecado depende de la relación que el alma entretiene con él o con el espíritu. [...] En cuanto al espíritu, parece tratarse de una entidad superior cuyo rol está esencialmente ligado al alma, pero que debe también ser salvado" (RouleauRoy (trad.), 1987, 127 ${ }^{20}$. El autor confirma que se trata de una antropología tripartita unitaria explicando que "el cuerpo no sabría pecar sin el alma que le da movimiento, pero el alma puede, en sentido inverso, ser « llenada » por el espíritu y llevar al cuerpo hacia su salvación" (Rouleau (trad.), 2007, 37 , nota $11,37-12,5)$.

Las consecuencias soteriológicas establecen que el alma que se aleja del espíritu se condenará a sí misma y al cuerpo. Es decir, existe una unidad interdependiente y dinámica entre los elementos componentes del ser humano cuyo ordenamiento final conlleva o niega la salvación. Este sistema dinámico es coincidente con el presente en los textos valentinianos posteriores que hemos analizado en el presente trabajo y en nuestro artículo anterior.

20 Por su parte, García Bazán explica en la nota 16 de su traducción: “Afirmación de la tricotomía espíritu, alma, carne-cuerpo. El cuerpo no se salva y la carne y el alma son transitorios". (García Bazán (trad.), 1999, 303, nota 16). 


\section{Conclusiones}

Hemos expuesto en primer lugar el pensamiento de Ireneo y esperamos haber explicado que su interpretación particular del sistema valentinano busca describir una antropología, una cristología y una soteriología que no son necesariamente falsas pero si expresamente simplificadas. Dicha postura, a nuestro entender, tiene por finalidad argumentar mejor, por oposición, su propio sistema soteriológico. En otras palabras, si bien puede matizarse que los autores valentinianos negaran la salvación del cuerpo, Ireneo necesita que así sea. Y esto radica en que el lionés parece entender la singularidad humana como proveniente de la recapitulación realizada por Jesús a través de su encarnación. Dicha recapitulación, que reúne lo espiritual y lo material, lo divino y lo humano, no solo ha sido querida por Dios para adaptarse a la antropología original sino que es indispensable para el sistema salvífico establecido por Ireneo.

Los autores gnósticos no niegan dicha singularidad sino que la entienden como una constitución tripartita del ser humano. Por ella desaparecen las categorías "raciales" impuestas por Ireneo y se elude todo determinismo. Su sistema dinámico lleva la soteriología un paso más allá, poniendo el acento en la salvación espiritual.

En efecto, nuestro análisis del pensamiento de Valentín y de tres de los textos que componen el Códice I, argumentan en ese sentido. Es así como el presente trabajo viene a completar, a modo de pre-cuela, lo expuesto por el artículo mencionado en la introducción. Hemos exhibido a través de un análisis textual de ambos trabajos, los fundamentos y la continuidad del sistema dinámico valentinano de las tres naturalezas.

Esta polémica entre heresiólogos y valentinianos sobre las relaciones entre antropología, cristología y soteriología se extienden desde Ireneo hasta Orígenes. Se trata de una polémica esencial de los primero siglos de los orígenes del Cristianismo que determinará la doctrina posterior. Tal como lo indica Alain Le Boulluec, los autores gnósticos buscan una profundidad mayor: "Cualquiera sea la perspectiva retenida, teológica o moral, los gnósticos cristianos no quieren proclamar una doctrina radicalmente diferente de aquella de la Iglesia; por el contrario, ellos pretenden superar una interpretación limitada del Evangelio para acceder a un sentido superior". ${ }^{21}$ Así, la finalidad de Ireneo excede objetivos

21 "Quelle que soit la perspective retenue, théologique ou morale, les gnostiques chrétiens ne voulent pas proclamer une doctrine radicalement différente de 
doctrinales específicos y se inscribe dentro de una lucha más amplia que busca negar a los gnósticos, y por ende a su particular sistema, la condición de cristianos. ${ }^{22}$

En este intento gnóstico de "ir más lejos y más profundo", la singularidad del hombre juega un rol preponderante. La exégesis valentiniana del mensaje del Salvador presenta desde sus orígenes un complejo sistema dinámico. Mientras que para los Padres analizados la cristología resume la antropología con fines salvíficos, para otros pensadores cristianos cristología y antropología son necesarias pero implican directa e idénticamente a la soteriología. Es decir la unidadsingularidad antropológica del hombre es indispensable para la formación gnóstica y la salvación de la semilla espiritual. Y es en esta semilla, en esta chispa de luz divina, en la cual reside la verdadera singularidad humana de los autores valentinianos.

\section{Referencias bibliográficas}

ATTRIDGE, H. W - MACRAE, G. W. (trad.) (1985). "The Gospel of Truth" en Krause, M. - Robinson, J.M. - Wisse, F. (eds.), Nag Hammadi Codex I (The Jung Codex), (Nag Hammadi Studies 22). Brill: Leiden.

BIANCHI, U. (1970). "Perspectives de la recherche sur les origines du Gnosticisme", en Bianchi, U (ed), Le Origini dello Gnosticismo. Colloquio di Messina 13-18 Aprile 1966. Brill: Leiden.

BIANCHI, U. (1970). "Le problème des origines du gnosticisme", en Bianchi, U. (ed), Le Origini dello Gnosticismo. Colloquio di Messina 13-18 Aprile 1966. Brill: Leiden.

BLANC, C. $\left(1996^{2}\right)$, Commentaire sur Saint Jean I (Livres I -V) (Sources Chrétiennes 120 bis). Cerf: Paris.

celle de l'Église, tout autre; ils prétendent dépasser une interprétation limitée de l'Évangile pour acceder à un sens supérieur. (Le Boulluec, 1985, 238).

22 "La représentation hérésiologique de l'exégèse gnostique, telle qu'elle se construit chez Irénée, a pour fin d'en nier le caractère chretien. [...] Le résultat es de priver d'existence l'exégèse gnostique. La controverse cependant ne peut dissimuler complètement ce qui fonde réellement la resemblance, et aussi la différence: la gnose chrétienne veut aller plus loin, plus profond que l'explication donnée par l'Église; cela suppose, de part et d'autre, le recours à une tradition. (Le Boulluec, 1985, 244). 
BLANC, C. (ed.) (1992). Commentaire sur Saint Jean IV (Livres XIX et XX), (Sources Chrétiennes 290). Cerf: Paris.

BOBICHON, Ph. (ed.) (2003). Justin Martyr, Dialogue avec Tryphon, II (Paradosis 47). Editions Universitaires: Fribourg.

CROUZEL, H. - SIMONETTI, M (eds.) (1978). Traité des Principes I (Sources Chrétiennes 252). Cerf: Paris.

--- (eds.) (1978), Traité des Principes II (Sources Chrétiennes 253). Cerf: Paris.

DUBOIS, J.-D. (2011). Jésus apocryphe, (Col. Jésus et Jésus-Christ 99). MameDesclée: Paris.

GARCÍA BAZÁN, F. (trad.) (1999). “Apócrifo de Santiago NHC I, 2" en Piñero, A. et alii (eds.), Textos gnósticos. Biblioteca de Nag Hammadi II: Apocalipsis y otros escritos. Trotta: Madrid.

--- (trad.) (1999). "Evangelio de la Verdad NHC I, 3" en Piñero, A. et alii (eds.), Textos gnósticos. Biblioteca de Nag Hammadi II: Evangelios, Hechos, Cartas. Trotta: Madrid.

--- (trad.) (2000). “Tratado Tripartito NHC I, 5" en Piñero, A. et alii (eds.), Textos gnósticos. Biblioteca de Nag Hammadi I: Tratados filosóficos y cosmológicos. Trotta: Madrid.

KING, K. L. (2003). What Is Gnosticism?. Harvard University Press: CambridgeLondon.

LE BOULLUEC, A. (1985). La notion d'hérésie dans la littérature grecque (II ${ }^{e}$ III $)$, Tome I de Justin à Irénée. Études Augustiniennes: Paris.

MAHÉ, J.-P. (trad.) (2007). “Traité sur la résurrection, NH I, 4", en Mahé, J.-P.Poirier. P.-H. (dir.). Écrits Gnostiques. Gallimard: Paris.

MÉNARD, J. E. (ed.) (1983). Le traité sur la résurrection (NH I, 4) (Bibliothèque Copte de Nag Hammdi 12). Les presses de l’Université de Laval: Québec. MONTSERRAT TORRENTS, J. - QUEVEDO, A. (trad.) (2000). "Tratado de la Resurrección NHC I, 4” en Piñero, A. et alii (eds.), Textos gnósticos. Biblioteca de Nag Hammadi II: Apocalipsis y otros escritos. Trotta: Madrid.

NORELLI, E. (1992). "Marcione e gli gnostici sul libero arbitrio, e la polemica di Origene", en Perrone, L. (ed.), Il cuore indurito del Faraone. Origene e il problema del libero arbirtrio. Marietti: Genova.

ORBE, A. (1958). Hacia la primera teología del Verbo. Estudios Valentinianos vol. 1/2, (Analecta Gregoriana). Universidad Gregoriana: Roma.

--- (1972). Parábolas evangélicas en San Ireneo, (BAC 331). La editorial católica: Madrid.

PAINCHAUD, L. - THOMASSEN, E. (trad.) (1989). Le Traité Tripartite (Bibliothèque Copte de Nag Hammadi 19). Les Presses de l'Université Laval: Québec. 
--- (trad.) (2007), “Traité Tripartite NH I, 5” en Mahé, J.-P. - Poirier, P.-H. (dir.), Écrits Gnostiques. Gallimard: Paris.

PASQUIER, A. - THOMASSEN, E. (trad.) (2007). "Évangile de la Vérité (NH

I, 3 ; XII, 2)”, en Mahé, J.-P. - Poirier, P.-H. (dir.), Écrits Gnostiques.

Gallimard: Paris.

ROULEAU, D. (trad.) (2007). “Épître Apocryphe de Jacques (NH I, 2)” en Mahé, J.-P. - Poirier, P.-H. (dir.), Écrits Gnostiques. Gallimard: Paris.

ROULEAU, D. - ROY, L. (trad.) (1987). L'Épittre Apocryphe de Jacques (NH I,

2) - L'Acte de Pierre (BG 4) (Bibliothèque Copte de Nag Hammadi 18).

Les Presses de l'Université de Laval: Québec.

ROUSSEAU, A. - DOUTRELEAU, L. (eds.) (1979). Contre les hérésies. Livre I, I (Sources Chrétiennes 263). Cerf: Paris.

--- (eds.) (1979). Contre les hérésies. Livre I, II (Sources Chrétiennes 264). Cerf: Paris.

--- (eds.) $\left(2002^{2}\right)$. Contre les hérésies. Livre III, II (Sources Chrétiennes 211). Cerf: Paris.

THOMASSEN, E. (2006). The Spiritual Seed. The Church of the "Valentinians", (Nag Hammadi and Manichaean Studies 60). Brill: Leiden-Boston.

TROIANO, M. (2014). “" De la substancia del diablo ». Orígenes y la dinámica del sistema valentinano de las tres naturalezas". Teología y Vida, 55/3, 607-629.

WILLIAMS, M. (1996). Rethinking "Gnosticism". An argument for dismantling a dubious category. University Press: Princeton New Jersey. 